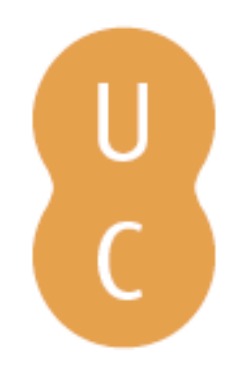

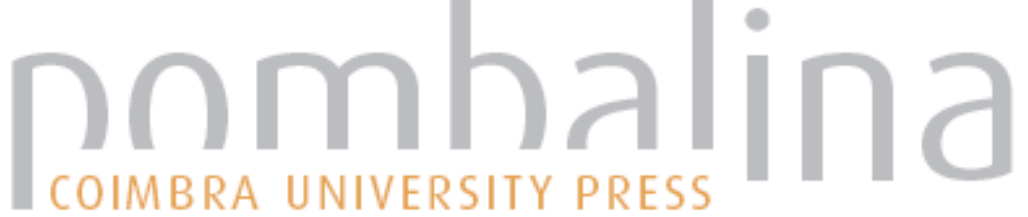

\section{Uma cascata de metáforas}

\author{
Autor(es): $\quad$ Pimenta, Alberto
}

Publicado por: Imprensa da Universidade de Coimbra

URL

persistente: $\quad$ URI:http://hdl.handle.net/10316.2/42341

DOI: $\quad$ DOI:https://doi.org./10.14195/978-989-26-1308-6_30

Accessed : $\quad$ 26-Apr-2023 14:05:06

A navegação consulta e descarregamento dos títulos inseridos nas Bibliotecas Digitais UC Digitalis, UC Pombalina e UC Impactum, pressupõem a aceitação plena e sem reservas dos Termos e Condições de Uso destas Bibliotecas Digitais, disponíveis em https://digitalis.uc.pt/pt-pt/termos.

Conforme exposto nos referidos Termos e Condições de Uso, o descarregamento de títulos de acesso restrito requer uma licença válida de autorização devendo o utilizador aceder ao(s) documento(s) a partir de um endereço de IP da instituição detentora da supramencionada licença.

Ao utilizador é apenas permitido o descarregamento para uso pessoal, pelo que o emprego do(s) título(s) descarregado(s) para outro fim, designadamente comercial, carece de autorização do respetivo autor ou editor da obra.

Na medida em que todas as obras da UC Digitalis se encontram protegidas pelo Código do Direito de Autor e Direitos Conexos e demais legislação aplicável, toda a cópia, parcial ou total, deste documento, nos casos em que é legalmente admitida, deverá conter ou fazer-se acompanhar por este aviso. 



\section{UMA CASCATA DE METÁFORAS}

Alberto Pimenta

Resumo: Problematizando os limites lógico-teóricos de gramaticalidade impostos ao discurso, este ensaio debruça-se sobre diferentes abordagens dos processos de significação e de simbolização. Sendo a metáfora uma funcionalidade da capacidade de simbolização e de representação do espírito humano, não é menos certo que, em toda a língua - que é sempre representação - todo o conhecimento humano assenta inevitavelmente na metáfora. Reconhecê-lo é o momento trágico de autoconhecimento a que a poesia se esforça por dar forma num tempo que nunca permanece.

Palavras-chave: conceito individual; conceito geral; logoforização; metáfora; metonímia; indizível; fingimento; credibilidade.

Abstract: Problematizing the theoretic and logic limits of a gramaticality imposed on discourse, this essay discusses different approaches to the signifying and the symbolizing processes. Metaphor being a function of the human spirit's capacity to symbolize and represent, it is equally true that in every 
language - which is always a representation - the whole of human knowledge is inevitably based on metaphor. The ability to recognise this is the tragic moment of self realization which poetry acknowledges and struggles to give form to in a time that never remains.

Keywords: individual concept: general concept; logophorization; metaphor; metonymy; unutterable; pretence; credibility.

Que diferença há entre usar uma casa para habitação, ou então usar para o efeito metade dum andar num prédio dito de condomínio? Alguma há, quer no que respeita à "causa material" e à "causa formal" do lugar escolhido para o fim indicado, quer na diferença que vai dum "domínio" para um "condomínio". No entanto, o cidadão que habita o seu andar refere-se invariavelmente à "sua casa".

Parece que aqui estaria um caso exemplar de metáfora segundo a definição de Aristóteles: um "trânsito" duma designação "estranha" ou "imprópria" do género para a espécie, ou da espécie para o género, ou de espécie para espécie, ou ainda por pura analogia. Ora os teorizadores das coisas da língua, neste caso, não falam de metáfora. Porquê? Será também que as categorias de Quintiliano (145) não servem aqui às mil maravilhas? O termo metafórico, diz ele, ou é necessário, ou mais expressivo, ou mais decente.

Quintiliano ocupa-se assim da razão discursiva da metáfora, enquanto os exemplos de Aristóteles ficam obscuramente pela sua qualidade semântica. Assim o "navio parado", exemplo cuja explicação nos é fornecida dizendo que ele está ancorado mas não parado. . porque balouça. Nesse caso, dizer que uma ave está parada quando não voa seria também metáfora, porque na sua qualidade de ser animado algum movimento sempre tem. Será que em grego 
a instrução semântica aponta mais para algo como imóvel? Mas mesmo assim, e ao fim da viagem, e em relação a ela, não há, no sentido próprio, imobilidade do navio até à viagem seguinte?

"Uma característica notável do pensamento de Aristóteles - como foi justamente observado - é a sua tendência para pedir ao conteúdo da linguagem a revelação de todas as espécies de relações, tanto naturais como morais" (Robin 85). Rossi-Landi (167) é ainda mais radical ao incluir Aristóteles naquele tipo de filósofos que, contentando-se com refletir sobre a língua na própria língua, mostram que são de opinião que isso é suficiente para esclarecer os problemas humanos em geral.

Dentro da perspetiva epistemológica que separa claramente a coisa e o conceito, pode dizer-se que Aristóteles é um dos que inauguram a autoalienação do pensamento ("Ao limitar-se à operação sistemática com meros conceitos, sem tomar em consideração a sua legitimidade material, o pensamento torna-se coisa" [MüllerStrömsdörfer 44]). O que espanta é que a moderna linguística continue em boa parte a proceder deste modo. $\mathrm{E}$ isto não se refere apenas ao uso das categorias retóricas, mas aos limites lógico-teóricos de gramaticalidade impostos ao discurso (v. Ian Robinson passim).

O exemplo dado de início é geralmente reconhecido como um caso de alargamento dum conceito individual concreto a conceito geral, alargamento que, pelo menos em certos casos pragmáticos, assim estabilizou, quer dizer, se tornou semanticamente estável. O conceito individual adquiriu uma espécie de livre-trânsito para se tomar conceito geral, livre-trânsito esse a que, certos lógicos, chamam logóforo.

Mas não é também através de uma logoforização implícita que se dá o alargamento de certos conceitos concretos originariamente muito bem determinados, sejam as "asas" do avião, as "pernas" da mesa ou os "frutos" do trabalho? Não é por se tomarem todos implicitamente conceitos gerais que ficam disponíveis para varia- 
das concretizações? Claro que não há nenhum inconveniente em considerar este trânsito um trânsito metafórico, isto é, que vai de conceito concreto para conceito concreto por pura analogia, final, ou formal, ou material. Simplesmente isso, nos casos em questão, além de constituir pura pré-história do conceito, escamoteia o facto de não poder haver classes diversas do mesmo conceito individual, sem que este se subordine explícita ou implicitamente a um conceito geral.

Portanto, em primeiro lugar, parece-me de utilidade separar as metáforas que resultam da formação de novas classes depois da generalização de conceitos individuais concretos dessas outras em que operam transversalidades simbólicas ou semióticas. Porque aqui estamos perante qualquer espécie de fronteira. Quer chamemos a tudo metáfora, quer distingamos, uma diferença há entre o mero alargamento semântico por motivos pragmáticos e o desvio de um campo semântico por motivos simbólicos, normalmente em clara subversão das normas de associação paradigmática. Claro que a distinção de vários tipos de metáfora tem muitos antecedentes. Desde Quintiliano até aos neoclássicos franceses estabelecem-se tipologias circunstanciais, sem grande fundamento filosófico ou linguístico. Assim, por ex., o jogo entre coisas animadas e inanimadas, com as quatro passagens possíveis que a metáfora opera a partir delas. Mas dada a fundamental impossibilidade de saber se os átomos e os astros são animados ou não, a distinção revela-se um mero formalismo.

O primeiro distinguo de causa em relação à metáfora e sua natureza partiu de alguns escolásticos (Curtius 6 1967: 228), que tentaram separar as águas entre a metáfora dos poetas (um fingimento para realçar a descrição, portanto, digamos, uma técnica discursiva) e a metáfora teológica (uma necessidade para representar aquilo que, em língua humana, não é representável, digamos então, uma técnica semântica). 
Dentro da distinção, é interessante observar que a metáfora teológica (semântica) seria o lugar-comum, ao contrário da poética (discursiva), essa sim realizadora de transversalidades simbólicas ou semióticas. Tão pragmáticas são as metáforas teológicas que, segundo informa J. A. Millán (10), as missões cristãs traduziram "Cordeiro de Deus" por "Foquinha de Deus" nas línguas da Lapónia. Ou então temos que dizer que o símbolo é devoluto, ou que se satisfaz com as funções do conceito geral. Com as funções do conceito geral parece satisfazer-se a "Cidade de Deus", e o pó que o homem é e em que se tomará (à parte a contradictio em termos de essência e de tempo, pois nada pode tomar-se no que já é) constitui em última análise um rebus químico de fácil solução, a menos que se considere que o polo da metáfora está no termo homem, porque o "pó" é o género que transitoriamente se fez a espécie "homem".

A metáfora poética é doutra natureza, mais complexa: "L'amour est un oiseau rebelle", canta Carmen na ópera de Bizet, e "Um amigo / é o lugar da terra / onde as maçãs brancas são mais doces" (Eugénio de Andrade 142). Carmen: eu não sou nem deixo de ser rebelde, nem é isso que afirmo ou não afirmo. Então é o amor que é rebelde? Claro que não: o amor (conceito geral do estado sentimental individual de Carmen) também não é rebelde; isso seria psicologicamente uma contradição. Não, o amor é um pássaro (transversalidade não semântica, mas semiótica), e os pássaros, esses sim, são rebeldes, não se deixam normalmente domesticar. É por deslizamentos metonímicos e por um salto semiótico de natureza metafórica que se infere que Carmen é rebelde. A asserção é metafórica, mas a rebeldia é metonímica: é uma questão semiótica, não simbólica.

Este é o caso comum da metáfora poética, que se move na fronteira da metonímia, e na fronteira entre o símbolo e a semiose. Poderá dizer-se: sou rebelde e não sou? Creio que não. Creio que terá de se dizer: sou rebelde, mas afirmo-o transversalmente. 
Ora isto é muito diverso do que Weinrich (333) afirma do "barco da nação". É ou não é um barco?, pergunta ele; e diz: "A resposta não pode deixar de ser: sim e não". Temos ad infinitum uma espécie de double bind: sim e não. Sendo assim, esta metáfora seria excelente para o não-comprometimento, mas menos recomendada para o discurso poético. E o exemplo de Eugénio de Andrade mostra-o claramente. É uma cadeia de tal transparência simbólica que a questão do "é e não é" nem se coloca. Não se coloca essa questão nem a do comprometimento ou não-comprometimento. Que diferenças dentro do fenómeno a que se chama metáfora!

Digamos que o discurso de Eugénio de Andrade liga elos antes soltos, estabelece uma cadeia não lexicalmente nem simbolicamente solidária, antes melodicamente solidária, no sentido técnico de melodia e no sentido técnico em que a solidariedade é aqui a harmonia das partes componentes. Como na música, opera-se através da metáfora a possibilidade de momentaneamente ouvir o indizível e assim experimentar a experiência de outro. Do outro. A metáfora poética é a comunhão interindividual do não representável em linguagem. Os escolásticos trocaram as coisas, porque esta metáfora é que aproxima a linguagem da divindade.

Bom, e que é que esta metáfora tem que ver com a metáfora do alargamento semântico? Susana R. Rivarola (53-4) recolheu algumas das mais curiosas definições de metáfora, da responsabilidade da moderna ciência da linguagem: "atribuição autocontraditória", "predicação contraditória" ou "contradeterminação", afirmação de "algo impossível" de acordo com os significados "usuais" das palavras relacionadas, "não-pertinência semântica", "quebra da congruência semântica", "não-solidariedade lexical", "incompatibilidade semântica", "combinação de signos apercebida como inusual e anómala", "forma normalizada de anomalia semântica" ou "quebra da isotopia do discurso", "distorções do material lexical", e mesmo "pequenos 'escândalos' semânticos”. 
Tudo isto é tão perturbante e sinal manifesto da tal autoalienação do pensamento esquecido da sua legitimação material, que a seguinte observação de S. J. Schmidt (1973) se revela lapidarmente pertinente: “. . . expressões com intenção referencial, quer dizer, [que podem ser] usadas para se referirem a correlatos extratextuais, não são signos ou etiquetas para "coisas", mas instruções. . . A questão da instrução semântica da referência duma expressão não pode ser portanto: Que designa a expressão x?, mas sim: Que instruções dá $\mathrm{x}$ ao alocutário no acto de comunicação típico? . . . As velhas distinções entre 'sentido' e 'significação', 'conceito' e 'significação', 'designado' e 'significado', etc, deviam nesta base desaparecer por completo, ou então ser reformuladas" (238).

Todorov (18-19) deu um passo importante no sentido do esclarecimento da questão, ao afirmar: "Si un auteur de l' époque classique emploie le mot 'flamme' dans un sens métaphorique, on ne peut pas affirmer qu' il veut dire amour. 11 veut nommer un sens qui ne peut être nommé avec exactitude par aucun autre signifiant. Le mot 'flamme' ainsi employé est le moyen le plus direct qui soit de signifier ce qu'il signifie. 'Flamme' ne signifie pas amour, au sens où 'amour' signifie amour'.

Todorov procede depois à distinção entre processos de significação e de simbolização, incluindo por exemplo, nos primeiros, a relação entre o significante "flamme" e o significado "flamme" e, nos segundos, a relação entre o significante "flamme" e o significado "amour". É uma distinção interessante e subtil, não fosse a significação ser também uma simbolização. Parece que mais exato seria falar de simbolizações de primeiro grau e de segundo grau, e até de terceiro e de quarto grau. Trata-se de uma cadeia infinita e, em cada caso, a escolha do elo parece obedecer aos critérios que S. J. Schmidt assim definiu (1971): "A escolha duma palavra para o lugar vazio dum texto depende da sua capacidade de realização dos valores funcionais ligados a esse espaço (eufónicos, rítmicos, sintácticos e 
semânticos)" (124). Schmidt está neste lugar a referir-se ao discurso poético, mas creio que o que diz, e ainda o que acrescenta acerca da impossibilidade de substituir um termo uma vez escolhido para o desempenho duma tarefa discursiva, se pode aplicar a qualquer discurso que obedeça a uma elocutio elaborada.

Vistas as coisas assim, a metáfora não se desvia de nenhum grau zero do discurso, nem substitui nenhum termo que seria o próprio: a metáfora é uma funcionalidade da capacidade de simbolização e de representação do espírito humano e, nessa condição, por certo, um dos universais do seu funcionamento. Isto abrange o simples alargamento pragmático de conceitos que estabilizaram na nova função, tanto como o mais subtil discurso poético, passando pela metáfora que abertamente sugere um comprometimento ou nãocomprometimento.

Afirmar, p. ex. que um vinho é um "néctar" é uma aliciante forma de não-comprometimento. Afirmar que ele tem "20 anos", quando porventura os não tem, é uma asserção comprovavelmente falsa, susceptivel mesmo de sanção penal. A metáfora (o "néctar") não obriga: gostos não se discutem.

Quando, no entanto, alguém fala hoje de "escravatura" e, segundo o gosto corrente, acrescenta "entre aspas", está com isso querendo declarar que usou o termo metaforicamente, isto é, impropriamente, porque a "escravatura" acabou. Nós sabemos que o que acabou foi a licença de uso do termo "escravatura" a conceptualizar certa relação de exploração do trabalho humano. Considerar que a abolição do termo trouxe consigo a abolição do facto da exploração em condições de total dependência económica e moral é pura coisificação da língua; acrescentar as tais "aspas", eventualmente com os indicadores levantados, é vénia à dita coisificação, isto é, compromisso aberto com ela e implícita renúncia a criticá-la.

Talvez a metáfora demonstre, para além das insuficiências conceptuais e designativas da língua, as próprias insuficiências inerentes ao 
conhecimento humano. De facto, todo o conhecimento experimental meramente subjetivo só é suscetível de exprimir-se em termos de conceptualização geral. Daí as metáforas que exprimem sensações reais do sujeito que, no entanto, não têm causa própria objetiva, visível ou material: são as "picadas" nos olhos sem que nada de exterior os pique, é o "peso" nas costas quando não há carga objectiva, é o "ardor" na pele quando nada a queima, etc.

A noção de insuficiência é tão grande que pede-se de empréstimo o termo que define a sensação quando há fenomenologia objectiva a provocá-la. A credibilidade é conseguida por meio dum fingimento. Mas não é esse o próprio papel da língua, ou de toda a representação? Então por que é que se finge que às vezes há fingimento, e às vezes não? Por que é que se fala de propriedade e impropriedade de termos e conceitos, se eles são também viajantes no tempo do discurso?

Onde o termo "metáfora" começa a ser realmente interessante é aqui mesmo, na fronteira do conhecimento, onde este começa por se revelar pura metáfora por entre metáforas. A este respeito, de resto, coincidem as Escrituras e os pensadores e poetas gregos, nos seus mitos fundadores.

Nos resultados a que chega e nos meios que para isso usa, o conhecimento humano é apenas uma metáfora. Exemplarmente o diz Fernando Pessoa, quando diz que com um novo Deus a verdade nem veio nem se foi, apenas o erro mudou.

Os primeiros homens reconheceram que estavam nus (Génesis 3, 7). Que espécie de aquisição de saber é esta? Não é um saber da coisa em si, porque antes já estavam nus. É um saber do valor simbólico ou representativo da coisa, é isso. Estavam nus, mas está-lo nada simbolizava. Conhecer é atribuir valor representativo àquilo que simplesmente é. Na sua génese e no seu resultado, o conhecimento é por conseguinte uma metáfora.

Esta metáfora resulta da separação do sujeito em sujeito e objeto de conhecimento, é portanto de natureza reflexiva. Não será 
a metáfora sempre uma certa forma de autoconhecimento, ou de projeção do sujeito no mundo? De facto, "o prado ri" porque o sujeito ri de o ver (ou simplesmente ri de satisfação), e "o rio chora" porque o sujeito chora de o ver (ou simplesmente chora de tristeza). A metáfora transpõe para o mundo a consciência subjectiva, desloca-a do conceito para a imagem.

Mas assim como os primeiros homens, no momento do autoconhecimento simbólico, decidem anulá-lo (tapando a nudez), assim a conceptualização do conhecimento humano decide anular o autoconhecimento instaurado pela metáfora, declarando-a um trânsito, um desvio. . . uma metáfora. Declarar que uma nova designação é metafórica é, de certo modo, anulá-la, ou pelo menos desautorizá-la.

Também Édipo, no momento do autoconhecimento, o nega, arrancando os olhos. Quando Weinrich diz que "o barco da nação" é e não é um barco, o que faz é repetir este gesto milenário de alargar e logo negar o conhecimento que se alargou.

A amada é "um anjo"? No próprio momento de o declarar, eis que se nega que o seja. E no entanto (Todorov o disse) não há outra designação que tão exactamente marque o que o amado quer exprimir: a sua consciência de que a amada lhe é superior a nível de manifestação física e espiritual, a sua entrega àquela que poderá ser um guia, como Beatriz no Paraíso, um certo pudor em aproximar-se e realizar uma troca humana de sentimentos, etc. Enfim, o indizível não é para ser dito ou, no ato de sê-lo, imediatamente se nega.

No Frei Luís de Sousa de Garrett, o conhecimento que vem trazer a catástrofe não se faz imediatamente simbólico, uma vez dito? Não traz consigo várias anulações, todas recolhidas no "Ninguém" do clímax? E a criança, na sua inocência, não se cansa de reiterar esse mesmo valor meramente simbólico dum tal conhecimento? As crianças não distinguem as designações consideradas próprias das metáforas. 
Claro que sem esta distinção não há catástrofe, apenas limbo. Neste sentido, pode afirmar-se que as designações correntes constituem um limbo (de espera, de insatisfação), enquanto as metáforas são o conhecimento que augura a catástrofe e, por isso, tratam de autonegar-se por vários modos.

Há uma dimensão que exclui a metáfora, que lhe não deixa lugar possível: o tempo. Com as mudanças que introduz mesmo no que é ou parece ser essência, o tempo é a grande metáfora. É como uma cascata: sempre o mesmo e sempre diferente. Incessantemente flui e se transforma e retoma a forma.

A propósito de poesia concreta, Siegfried J. Schmidt (1971) fala de "Ainda-língua" e "Já-língua", "Já-sentido" e "Ainda-sentido" (148). Creio que assentaria perfeitamente àquilo a que se chama metáfora, pelo menos no momento da sua criação, porque a passagem do tempo acaba por negá-la duma ou doutra maneira: considerando-a uma falsidade, ou recuperando-a para o lugar-comum das designações.

\section{Obras citadas}

Andrade, Eugénio de. "Poesia e Prosa". O Jornal. Lisboa: 1990. Print.

Curtius, Ernst Robert. Europäische Literatur und Lateinisches Mittelalter. Berna e Munique: Francke Verlag, 1967. Print.

Millán, José Antonio. "Del Celeste Tio Materno o Traducir implica todo". Barcelona, Quimera IX-X (1981): 40-41. Print.

Müller-Strömsdörfer, Ilse. "Die 'Helfende Kraft Bestimmter Negation': Zum Werke Th. W. Adornos”. Ed. Rüdiger Bubner et al. Kritik und Interpretation der Kritischen Theorie. Haia: Dutch Editing Company, 1971. Print.

Quintiliano. Instituições Oratórias. Trad. Jerónimo Soares Barbosa. Coimbra: Imprensa da Universidade, 1836. Print.

Rivarola, Susana Reisz de. "Predicación metafórica y discurso simbólico". Lima, Lexis 1.1 (1977): 51-99. Print.

Robin, Léon. A Moral Antiga. Trad. João Morais-Barbosa. Porto: Despertar, s.d. Print.

Robinson, Ian. The New Grammarians' Funeral: A Critique of Noam Chomsky's Linguistics. Cambridge: Cambridge University Press, 1975. Print. 
Rossi-Landi, Ferruccio. Dialektik und Entfremdung in der Sprache. Trad. Arno Widmann. Franfurt/M: Makol, 1973. Print.

Schmidt, Siegfried J. Ästhetische Prozesse: Beiträge zu einer Theorie der nichtmimetischen Kunst und Literatur. Colónia e Berlim: Kiepenheuer \& Witsch, 1971. Print.

- "Texttheorie/Pragmalinguistik". Ed. Hans Peter Althaus et al. Lexicon der Germanistischen Linguistik. Tübingen: Niemeyer, 1973. 233-44. Print.

Todorov, Tzvetan. "Synecdoques". Sémantique de la poésie. Paris: Seuil, 1979. Print.

Weinrich, Harald "Semantik der kühnen Metapher". Deutsche Vierteljabrsschrift für Literaturwissenschaft und Geistesgeschichte III. Stuttgart: 1963. Print. 